\title{
Risk assessment of Produced water discharges on Sediment and Water of Forcardos River, Niger Delta, Nigeria.
}

\author{
O.U. Oyesanya \\ University of Nigeria Nsukka \\ oluwaseun.oyesanya@unn.edu.ng
}

\begin{abstract}
This paper presents an evaluation of contamination effects from produce water released into water and sediments of the Forcados River, Nigeria. Nineteen water samples and nineteen sediment samples were examined for physicochemical parameters, organic hydrocarbons, and heavy metals. Heavy metal pollution index (HPI) and metal index (MI) were used to determine the degree of pollution of the river water by heavy metals while geo-accumulation index (Igeo), contamination factor $(\mathrm{CF})$, enrichment factor $(\mathrm{EF})$, and pollution load index (PLI) were used to assess the degree of pollution by heavy metals in the river sediments. The calculated HPI for drinking purposes revealed that all the water samples belong to the high pollution class (HPI $>30$ ) while MI for irrigation purposes showed that the water of the river is slightly contaminated $(\mathrm{MI}<2.02$. Igeo, $\mathrm{EF}$, and $\mathrm{CF}$ showed high contamination of the river sediments by $\mathrm{Cd}, \mathrm{Pb}, \mathrm{Ba}, \mathrm{Cr}$, and Fe. The PLI revealed that 8 of the sediment samples showed progressive deterioration. As, $\mathrm{Ba}, \mathrm{V}, \mathrm{TPH}, \mathrm{BTEX}$, and PAH in the river water and $\mathrm{Cd}, \mathrm{Pb}, \mathrm{Ba}, \mathrm{PAH}, \mathrm{TPH}$ and phenol in the river sediment recorded their most elevated concentration at the point of discharge (DP). The heavy metals, As, $\mathrm{Ba}, \mathrm{V}, \mathrm{Cd}$, and $\mathrm{Pb}$ are assumed to be released from produce water because they recorded their highest concentration at DP and have high correlation coefficient values with the organic species (BTEX, TPH, PAH, and Phenol). In light of these discoveries, obviously the make-up and quality of river water and sediments of Forcados River are being changed by hydrocarbon constituents and heavy metals from brine water releases.
\end{abstract}

Keywords: Heavy-metals, Produced water, Forcados River, Water pollution and Sediments pollution. 